D:INsurglVol. 24, No. 1, Jan. - Mar., 2020\Nsurg-9.Doc $\quad$ Fig. 1-7 Color $\quad$ (A) P. $2-7 \quad$ II
REVIEW ARTICLE

\title{
Brain Death Islamic Perspective
}

\author{
FAUZIA SAJJAD ${ }^{1}$, REHAN SHAHID ${ }^{2}$, MUKHTIAR AHMED ${ }^{3}$, ZAIN SALEH ${ }^{1}$, AHSAN ARIF $^{2}$, \\ SUNDUS ALI ${ }^{4}$, MUHAMMAD AKMAL ${ }^{1}$, KAMRAN KHAN ${ }^{2}$, SAIMA ASHFAQ ${ }^{5}$, AFTAB \\ YOUNAS $^{2}$ \\ ${ }^{1}$ Department of Neurosurgery, Punjab Institute of Neurosciences (PINS), Lahore, Pakistan. \\ ${ }^{2}$ Department of Cardiothoracic Surgery, Punjab Institute of Cardiology (PIC), Lahore, Pakistan. \\ ${ }^{3}$ Khairpur Medical College, Khairpur, Pakistan. \\ ${ }^{4}$ Mayo Hospital, Lahore, Pakistan. \\ ${ }^{5}$ Jamiat-ul-Madina, Lahore, Pakistan.
}

DOI: 10.36552/pjns.v24i1.395

Death follows the footsteps of life. It wears the invisible cloak. It chases life silently and finally ceases it. To diagnose and declare death is complex. Moral, social, legal, medical, ethical and religious issues make it more complex. ${ }^{1}$ The Western world has their own definite modern criteria for Do Not Resuscitate and declaration of death. They favor mercy killing and euthanasia to give relief to patient from pain and worries of life. ${ }^{2}$ In such circumstances the Islamic perspective of brain death seems dubious and gloomy, which in fact are not.

Medical science declares patient dead when it has permanent absence of all brain functions specifically the brainstem characterized by absent brainstem reflexes, apnea and loss of consciousness. ${ }^{3}$ Internationally, there are two famous diagnostic brain death guidelines. One is the code for declaration of brainstem death in the United Kingdom and the other one are guidelines for brain death declaration by The Neurological American Academy. ${ }^{4,5}$

UK code is basically the declaration of death by neurological assessment after fulfillment of important preconditions and excluding potential reversible states of apnea. Officially patient is declared dead after confirmation of apnea, loss of consciousness and the absent brainstem reflexes. The different components of cranial nerves are examined for integrity of brainstem reflexes. The apnea test is performed after confirmed absent brain stem reflexes. Apnea test is performed by inducing acidaemia for respiratory stimulation with a $\mathrm{pH}$ of less than 7.4 , without causing hypoxia and hemodynamic instability, and absence of respiratory effort is confirmed. It is necessary to evaluate both components of tests (brain stem reflexes and apnea) twice in the presence of two authentic qualified doctors. ${ }^{3,4}$

The American Academy of Neurology confirmed death not only by demonstration of absence of brainstem reflexes and apnea testing, but also by utilizing the auxiliary testing of cortical activity. They believe that death cannot be declared if there is persistent activity of the cerebral cortex in the presence of absent brainstem functions. They are dependent on auxiliary brain testing like EEG of 30 minutes duration or demonstration of loss of blood flow to brain by Doppler or CT Angiogram or Magnetic Resonance Angiogram. They follow the same prerequisites and preconditions prior to neurological assessment as well as the qualification criterion for declaration of death. ${ }^{5,6}$

In Islam, the concept of death is separation of soul from body. Body is the home for soul, taking up of the soul is accomplished by ALLAH All Mighty. By His order the angel of death, Malak-al-Maut (Hazrat Izraeel A.S) will take the soul out of the body. Muslims believe that we are mortal, everyone has to die by the order of God. ${ }^{7}$ Chapter 39, Surah Al-Zumar Verse 42 clearly explains this fact that its ALLAH Almighty Who takes souls. 
42. Allah fully takes away the souls (of the people) at the time of their death, and (of) those who do not die, in their sleep. Then $\mathrm{He}$ withholds those on whom He had decreed death, and sends others back, up to an appointed term. Surely, in this, there are signs for a people who ponder.

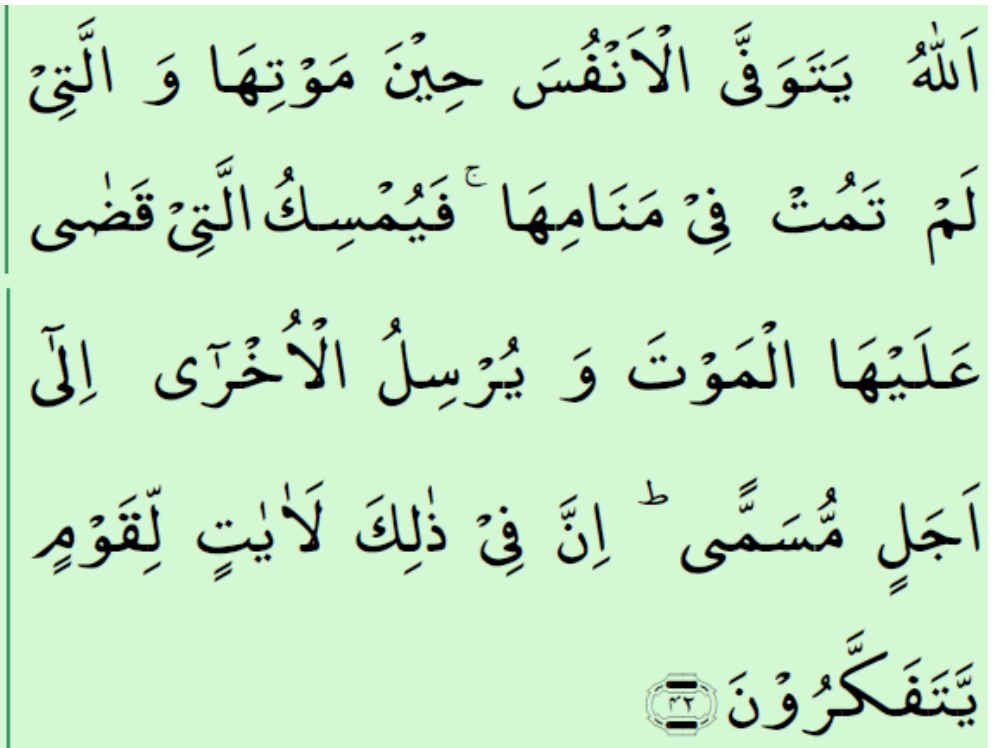

(Translated by Justice Mufti Taqi Usmani)

Islam ascertains that we are mortals and we have to die. In Quran multiple times death and life hereafter is discussed.

Chapter 3 Surah Al Imran, verse 185 of Quran describes openly.

185. Every soul has to taste death. It is on the Day of Judgement that you shall be paid your rewards in full. So, whoever has been kept away from the Fire and admitted to Paradise has really succeeded. The worldly life is nothing but an illusionary enjoyment.

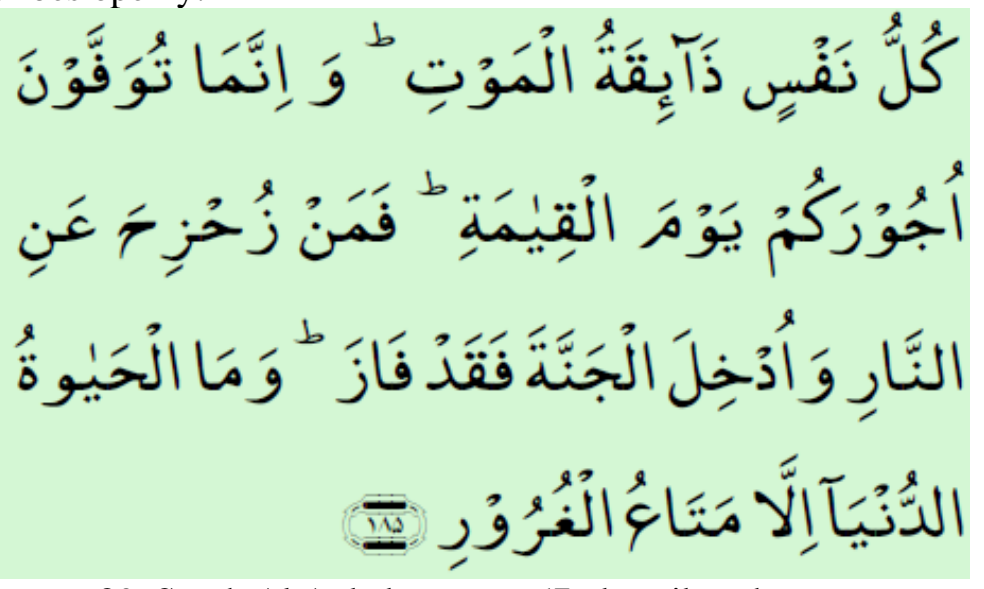

(Translated by Justice Mufti Taqi Usmani) Chapter 29, Surah Al Ankabut verse 57, describes the same.

57. Every person has to taste death, then to Us you are to be returned.

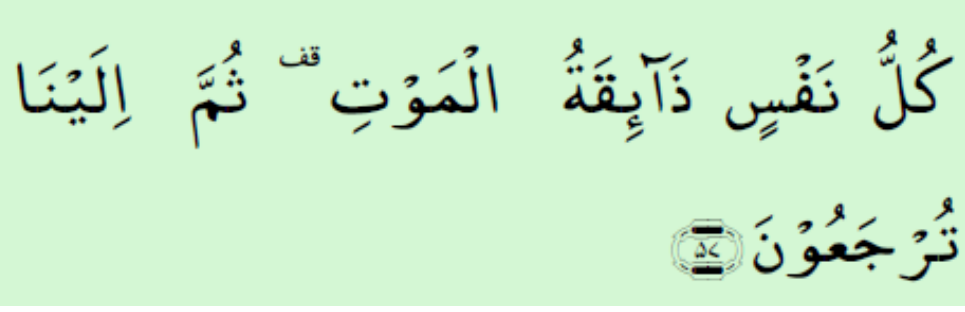

(Translated by Justice Mufti Taqi Usmani) 
The authentic book of Ahadis, Sahih Al Bukhari, Hadees-e-Mubaraka no. 3036, 'Abdallah Ibne Mas'ud recalled that God's Messenger said:

Each one of you collected in the womb of his mother for forty days, and then turns into a clot for an equal period (of forty days) and turns into a piece of flesh for a similar period (of forty days) and then Allah sends an angel and orders him to write four things, i.e., his provision, his age, and whether he will be of the wretched or the blessed (in the Hereafter). Then the soul is breathed into him...(Sahih al-Bukhari: 6594).

Here it is very important that soul house the body at $120^{\text {th }}$ day of gestation while heartbeat comes at $90^{\text {th }}$ day. Our belief is that life is with the soul and separation of the soul is death.

It's difficult to gauge the separation of soul from body, the more who will decide soul has been separated. Whether being a Muslim should we declare death when the patient is brain dead or wait for cardiopulmonary arrest $?^{8,9}$ Should we withdraw life support? ${ }^{78}$. While doing this whether we are lessening the miseries of patient of we are committing a sin?

\section{For this reason, We decreed for the} children of Isra'il that whoever kills a person not in retaliation for a person killed, nor (as a punishment) for spreading disorder on the earth, is as if he has killed the whole of humankind, and whoever saves the life of a person

is as if he has saved the life of the whole of humankind. Certainly, Our messengers have come to them with clear signs. Then, after all that, many of them are there to commit excesses on the earth.

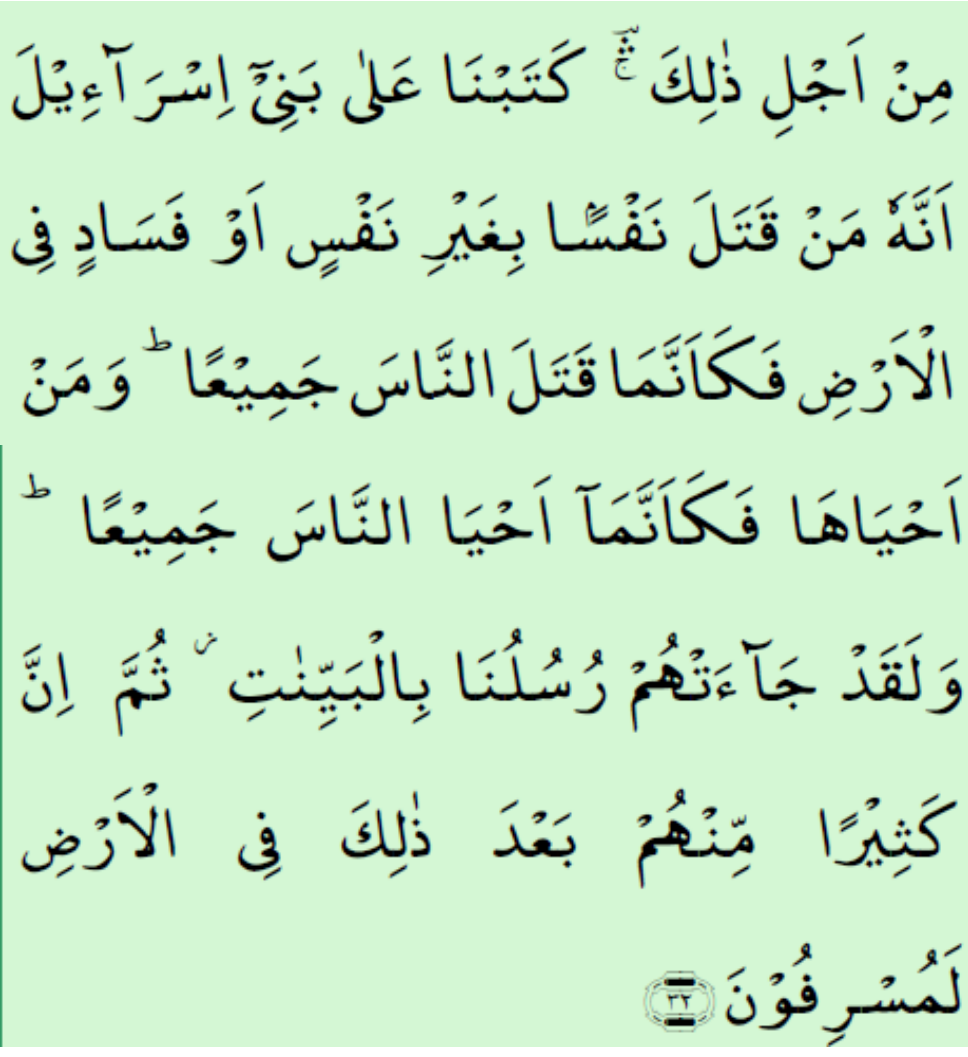

Chapter 5, Surah Al-Maidah Verse. No. 32, narrates (Translated by Justice Mufti Taqi Usmani).

Being a Muslim we respect human life. It's our belief that life is a gift of God; it's only He who can give and take life. We also believe that illness is from God either to lessen our miseries or to test our faith. Chapter 26 Surah Ash Shuara verse 80 narrates.
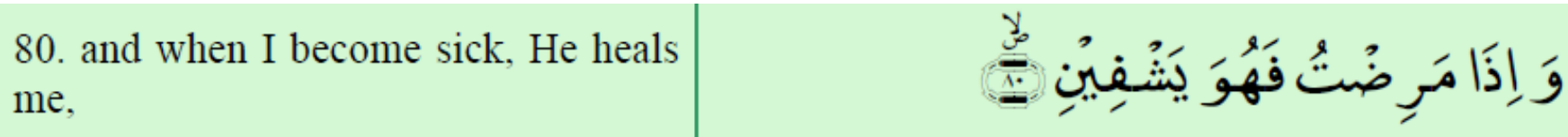

(Translated by Justice Mufti Taqi Usmani) 
To seek cure for disease, and to treat illness was the custom \& practice of prophets. ALLAH Almighty is the one who gave us cure in illness.

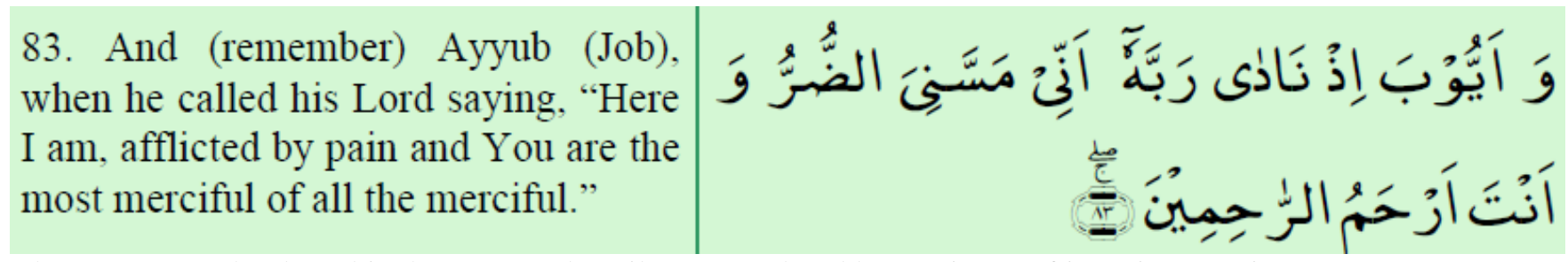

Chapter 21 Surah Al Ambiyah verse 83 describes (Translated by Justice Mufti Taqi Usmani)

Till how long should we treat illness \& when to withdraw?

When the pearls of wisdom and knowledge are scattered on the pages of the Quran, in the sayings and deeds of our beloved Holy Prophet Muhammad (P.B.U.H.), saved as a genre of literature the Ahadis-eMubaraka, and everyone makes his or her own perception and reflection without understanding the context, circumstances and facts, then answer should be searched in precedence of analogy (Qiyas) and consensus of religious scholars (Ijmah) ${ }^{7,8,10}$

Permanent Committee for Islamic Research \& Issuing Fatwa issued Fatwa by consensus of religious scholars (Ulma) of different sects. Fatwa No 12086/ 1409(1989).

The salient features of fatwa are:

- If a person arrives in hospital is already dead.

- If medical file stamped do not resuscitate \&patient unsuitable for resuscitation.

- If three physicians considered inappropriate to resuscitate, for irremediable disease \& death is almost certain.

- If the patient is physically \& mentally incapacitated and suffering from severe disease and DNR already decided by three authorized physicians.

- If the patient has irremediable brain damage authenticated by three specialist physician.

- If resuscitative measures considered unless \& incongruous for that specific patient.

This fatwa addresses all questions raised regarding resuscitative measures and suitable candidates for resuscitation. The important thing is that hydration and feeding should continue till end of life. Hydration and feeding are not included as resuscitative measures. ${ }^{7,11}$

Euthanasia, also known as mercy killing, is extremely prohibited in Islam. It's the right of God to give life and to take life. Muslims believe life is a precious gift of God; it should be respected and should be laid down according to God's will. We as Muslims have strong belief that there is a fixed date of death when souls will be taken out from the body. ${ }^{10,11}$ This is also cleared from Ahadis-e-Mubarika.

Islamic Fiqh Academy [IFA] of the Organization of the Islamic Conference (OIC) tried to legitimize the brain death criteria according to Islamic laws.

They finally concluded and reached a decision at their annual session in Amman, Jordan, in 1986. They declared in resolution 5 that:

A person is considered to be legally dead and all Shariah principles can be applied if any of the following signs is established:

- Complete heart and breathing stoppage and doctors establish it is irreversible.

- Complete cessation of all vital brain functions, and doctors conclude it is permanent and the brain has begun to degenerate.

In these cases, it is justifiable to discontinue life support even if some systems (e.g. heart) continue their automated function under the life supporting devices effect. ${ }^{12}$

IFA (Islamic Fiqh Academy) of MWL (Muslim World League) did a remarkable job and added new decisions regarding brain death. They finished the debate about brain stem death or real death in Islam. They issued their ruling in 1987 and concluded that the brain death criteria could be implemented only when three competent specialist doctors have consensus on irreversible brain death. The most important aspect was they explicit clearly that cardiac death and brain death are not equal. Life support can be stopped despite the presence of pumping heart and artificial respiration with the help of a ventilator. But The Sharia legal consequences can only be effective after cessation of circulation and respiration. .,13 $^{73}$

A briefing on Medical Ethics, (IMANA Perspective) was developed in 2003 by IMANA (Islamic Medical Association of North America). They recapitulate accepted criteria of Brain Death by 
Islamic Fiqh Academy, and clarify the ambiguity regarding who will determine death. Moreover the competency of physician needed for declaring death. ${ }^{8,13,14}$

There was great conflict regarding brain death and organ transplantation in Egypt. One Egyptian professor campaigned against brain death not only in medicine circles, but also on media. The issue was discussed with Jamia-al-Azhar. Few members participated in an international conference of bioethics and then discussed with eminent Muslim scholars and finally legislations were made with the approval of Jamia Al-Azhar that organ transplantation from a patient will only be feasible after complete cessation of brain and heart functions. ${ }^{7,8}$

In different Islamic countries, there are legal and judicial bodies that made legislation, according to Islamic laws to make judicial decisions on brain death. They made notable Sharia judicial decisions on brain death. In India, Mufti Zainul Islam Qasmi Allahabadi, Darul Ifta, Dar-ul-Uloom Deoband, India have certified Fatwa that if doctors confirm that the patient has an irreversible cessation of brain function, then the life support can be withdrawn (Fatwa No. 284/217/ $S N=3 / 1441$ ).

In short, mostly Islamic countries believe and make decisions according to IFA-OIC and IFA-MWL.

In Pakistan, there are different sects and people believe on their respective Islamic scholars. Allama Taqi Usmani is the most eminent Muslim scholar of Jamia Usmania, Karachi. He is a lifelong member of the both IFA-OIC and IFA-MWL, so Jamia Usmania and their followers believe in the fatwa of IFA-OIC and IFA-MWL. Dr. Israr Ahmad, the founder of Tanzeem-e-Islami. The fiqah counsel of Tanzeem-eIslami also made the decision that the life support removal is permissible if there is no chance of recovery and patient is brain dead. The Jamiat-ulMadina, Lahore believed if three authentic doctors confirmed brain death and there is no chance of recovery then patient can be declared dead. Mufti Abdul Waheed of Jamiat-ul-Madina wrote in his book, 'Mareez o Mualij kay Islami Ehkaam', in chapter 50 of brain death that it would be useless to continue artificial respiration if brain death has been declared by three authentic authors. ${ }^{15}$

\section{CONCLUSION}

Finally, we can conclude that we Muslims are not of the stone ages, Our Allah and Prophet Muhammad (P.B.U.H) gave us proper guidance even fourteen hundred years ago, regarding death and its declaration. There is consensus among all Fuqaha that in case of brain damage/death there is permissibility to discontinue life support treatment, but opinion differs regarding the actual time of death and its sharia and legal implications and organ harvesting which should not be done until the patient has died completely from the sharia point of view.

\section{Additional Information:}

This paper was presented as oral presentation in ICRAN 2019, in Peshawar on November 15, 2019 by Dr. Fauzia Sajjad under tile of Brain Death: An Islamic Perspective.

\section{REFERENCES}

1. Miller AC. Opinions on the legitimacy of death declaration by neurological criteria from the perspective of 3 abrahamic faiths. Medeniyet Med J. 2019; 34: 30513 .

2. Math SB, Chaturvedi SK. Euthanasia: right to life vs. right to die. Indian J Med Res. 2012; 136 (6): 899-902.

3. Powner D.J Certification of brain death: take care, 2009; 373 (9675): P1587-1589.

4. Jennett B, Gleave J, Wilson P. Brain death in the neurosurgical units. Br Med J (Clin Res Ed). 1981; 282 (6263): 533-539.

5. The American Academy of Neurology (AAN) guideline update (Neurology $\left.{ }^{\circledR}\right)$ on determining brain death in adults, 2010; 74: 1911-1918.

6. Wijdicks EF, Varelas PN, Gronseth GS, Greer DM; American Academy of Neurology. Evidence-based guideline update: determining brain death in adults: report of the Quality Standards Subcommittee of the American Academy of Neurology. Neurology, 2010; 74 (23): 1911-1918.

7. Chamsi-Pasha H, Albar, MA. Do not resuscitate, brain death, and organ transplantation: Islamic perspective. Avicenna Journal of Medicine, 2017; 7 (2): 35-45. Doi:10.4103/2231-0770.203608.

8. Miller AC, Ziad-Miller A, Elamin, EM. Brain death and Islam: the interface of religion, culture, history, law, and modern medicine. Chest, 2014; 146 (4): 10921101. Doi:10.1378/chest.14-0130.

9. Grundmann J. Shari'ah, brain death, and organ transplantation: the context and effect of two Islamic legal decisions in the Near and Middle East. Am J Islamic Soc Sci. 2005; 22 (4): 1-25.

10. Babgi A. Legal issues in end-of-life care: perspectives from Saudi Arabia and United States. Am J Hosp 
Palliat Care, 2009; 26 (2): 119-127.

11. Arbour R, AlGhamdi HM, Peters L. Islam, brain death, and transplantation: culture, faith, and jurisprudence. AACN Adv Crit Care, 2012; 23 (4): 381-394.

12. Fiqh Academy Book of Decrees. Third Conference of Islamic Jurists. Amman, Jordan, 1986; Decree No. 5.

13. Ebrahim AF. Islamic jurisprudence and the end of human life. Med Law, 1998; 17 (2): 189-196.

14. Atighetchi D. Islamic Bioethics: Problems and Perspectives. Dordrecht, The Netherlands: Springer; 2007.

15. Wahid A. Mareez-O-Muaalij Kay Islami Ahkaam, 2018; (4): 317.

\section{Additional Information}

Disclosures: Authors report no conflict of interest.

Ethical Review Board Approval: The study was conformed to the ethical review board requirements.

Human Subjects: Consent was obtained by all patients/participants in this study.

Conflicts of Interest: In compliance with the ICMJE uniform disclosure form, all authors declare the following.

Financial Relationships: All authors have declared that they have no financial relationships at present or within the previous three years with any organizations that might have an interest in the submitted work.

Other Relationships: All authors have declared that there are no other relationships or activities that could appear to have influenced the submitted work.

Address for Correspondence:

Dr. Zain Saleh

Department of Neurosurgery, Unit II, Punjab Institute of Neurosciences (PINS), Lahore

Email: zainsauleh@gmail.com

\begin{tabular}{|l|l|l|l|}
\hline \multicolumn{3}{|c|}{ AUTHORSHIP AND CONTRIBUTION DECLARATION } \\
\hline Sr.\# & Author's Full Name & Intellectual/Contribution to Paper in Terms of: \\
\hline 1. & Fauzia Sajjad & $\begin{array}{l}\text { 1. } \text { Proposed topics and Basic Study Design, } \\
\text { methodology, manuscript writing }\end{array}$ \\
\hline 2. & Rehan Shahid & 2. Data collection and calculations \\
\hline 3. & Mukhtiar Ahmad & 3. Analysis of data. \\
\hline 4. & Zain Saleh & 4. $\begin{array}{l}\text { Literature review and manuscript writing, } \\
\text { paper writing }\end{array}$ \\
\hline 5. & Ahsan Arif & 5. Paper writing \\
\hline 6. & Sundus Ali & 6. Paper writing \\
\hline 7. & Muhammad Akmal & 7. Literature review \\
\hline 8. & Kamran Khan & 8. Data collection and calculations \\
\hline 9. & Saima Ashfaq & 9. Data collection \\
\hline 10. & Aftab Younus & 10. Literature review \\
\hline
\end{tabular}

Date of Submission: 20-1-2020

Date of Revision: 02-03-2020

Date of Online Publishing: 31-03-2020

Date of Print: 31-3-2020 